\title{
Levels of Contamination by Perfluoroalkyl Substances in Honey from Selected European Countries
}

\author{
Magdalena Surma $^{1} \cdot$ Henryk Zieliński ${ }^{2} \cdot$ Mariusz Piskuła $^{2}$
}

Received: 29 November 2015/Accepted: 18 May 2016/Published online: 27 May 2016

(c) The Author(s) 2016. This article is published with open access at Springerlink.com

\begin{abstract}
Perfluoroalkyl substances (PFASs) are manmade chemicals manufactured for numerous applications. The aim of this study was to assess the levels of 10 PFASs in selected types of honey samples from selected eastern, northern and southern European countries. A total of 26 samples of honey were analyzed. PFCAs (perfluoroalkyl carboxylic acids) were detected in almost all (92\%) analyzed samples in the range of $0.124-0.798 \mathrm{ng} \mathrm{g}^{-1} \mathrm{ww}$ (wet weight). The average concentrations of particular PFCAs $\left(\mathrm{ng} \mathrm{g}^{-1} \mathrm{ww}\right)$ in honey samples increased in the following order: perfluorononanoic acid $(0.164)<$ perfluorooctanoic acid $(0.189)<$ perfluoroheptanoic acid $(0.271)<$ perfluorodecanoic acid (0.278). Amongst perfluoroalkane sulfonates, only perfluorohexane sulfonate (PFHxS) was identified in four of 26 analyzed samples, and its concentrations ranged from 0.080 to $0.191 \mathrm{ng} \mathrm{g}^{-1} \mathrm{ww}$. Italian eucalyptus honey contained the highest total content of PFASs (0.878 $\left.\mathrm{ng} \mathrm{g}^{-1} \mathrm{ww}\right)$. Samples originating from an industrial region of Poland showed $20 \%$ higher concentrations of PFCAs compared to those from non-industrial regions.
\end{abstract}

Keywords PFASs · PFCAs · PFSAs $\cdot d$-SPE $\cdot$ Honey $\cdot$ micro-HPLC-MS/MS

Magdalena Surma

m.surma@ur.krakow.pl

1 Malopolska Centre of Food Monitoring, Faculty of Food Technology, University of Agriculture in Krakow, 122, Balicka str., 30-149 Krakow, Poland

2 Department of Chemistry and Biodynamics of Food, Division of Food Science, Institute of Animal Reproduction and Food Research of the Polish Academy of Sciences, 10, Tuwima str., 10-748 Olsztyn, Poland
Perfluoroalkyl substances (PFASs) are a group of organofluorine compounds, i.e., aliphatic hydrocarbons with all or almost all hydrogen atoms replaced with fluorine. PFASs can be distinguished into two main groups: perfluoroalkyl carboxylic acids (PFCAs) and perfluoroalkane sulfonates (PFSAs) (Buck et al. 2011). Due to the strength of the C-F bond, they are highly chemically stable and highly resistant to biological degradation. Therefore, these compounds tend to persist in the environment and have been proposed as a new class of persistent organic pollutants (Stahl et al. 2011). Human exposure to PFASs can be due to a variety of environmental and product-related sources. The greatest portion of chronic exposure to PFASs has been suggested to be the result of intake of contaminated foods, including drinking water (Del Gobbo et al. 2008; Domingo 2012; Ericson et al. 2008; Gellrich et al. 2013; Kärrman et al. 2007; Zhao et al. 2012).

Honey is a natural food, composed mainly of a complex mixture of carbohydrates and other minor substances such as organic acids, amino acids, proteins, minerals, vitamins and lipids (Finola et al. 2007). Honey is produced by honey bees from the nectar of blossoms or from the secretions of living parts of plants. It is also an inexpensive product available for novel therapies against bacterial infections (Huttunen et al. 2012). The clinical use of honey has enormous potential, especially in the fight against antibiotic-resistant strains (Huttunen et al. 2012; Kwakman et al. 2008; Mercan et al. 2007). Due to the world-wide consumption of honey, especially among children, there is a demand for honey that is free from contaminants such as persistent organic pollutants, including the compounds of interest in this study. The specific composition of any batch of honey, including contaminants, depends on the crops surrounding the beehive (Aliferis et al. 2010; Kujawski and Namieśnik 2008). The 
occurrence of PFASs in honey results from bees collecting nectar from contaminated flowers (Celli and Maccagnani 2003), which in turn can be contaminated by soil, air and water. Therefore, honey may serve also as an indicator of environmental pollution by PFASs.

Currently, there is no legislation concerning PFASs in food or feed within the EU (EFSA 2008). The limited scope of research and preliminary findings of EFSA indicate the need to identify PFASs in raw material as well as in food of plant origin in order to reveal the present scale of their occurrence and the associated risk to human health (Surma and Zielinski 2015). To estimate the extent of their presence in food, in March 2010, Commission Recommendation 2010/161/EU invited the Member States to monitor the presence of perfluorooctane sulfonates (PFOSs) and perfluorooctanoic acids (PFOAs) (compounds similar to PFASs but with different chain lengths) and their precursors (EU Recommendation No. 161, 2010).

The aim of this study was to assess levels of PFAScontamination in honey samples from selected eastern, northern and southern European countries. Amongst PFASs, selected perfluoroalkyl carboxylic acids (PFCAs), such as perfluorobutanoic acid (PFBA), perfluoropentanoic acid (PFPeA), perfluorohexanoic acid (PFHxA), perfluoroheptanoic amid (PFHpA), perfluorooctanoic acid (PFOA), perfluorononanoic acid (PFNA) and perfluorodecanoic acid (PFDA), as well as perfluoroalkane sulfonates (PFSAs) such as perfluorobutane sulfonate (PFBS), perfluorohexane sulfonate (PFHxS) and perfluorooctane sulfonate (PFOS), were determined using a micro-HPLC-MS/ MS system, after being subjected to dispersive solid phase extraction ( $d$-SPE). The analyzed honey samples originated from seven EU countries (eastern Europe-Poland and Slovakia; southern Europe-Italy, France and Spain; northern Europe-Scotland and England). Due to the necessity of the better research of the Polish retail market, the honey was also collected from industrialized regions of Poland (Malopolska) as well as non-industrial regions (Warmia and Mazury) called "the green lungs of Poland". Sixteen types of honey collected for the study were as follows: heather, clover, wildflower, multiflorous, linden, rape, buckwheat, forest, honeydew, lemon and orange blossom, thyme, eucalyptus, chestnut, acacia and lavender. These honey samples were representative of three geographic regions of Europe, each differing in climatic, environmental and socio-economic conditions.

\section{Materials and Methods}

According to Commission Recommendation 2010/161/EU, it is required to use a method of analysis that has been proven to generate reliable results. Currently, due to its high sensitivity and selectivity, liquid chromatography hyphenated with tandem mass spectrometry (LC-MS/MS) operating in the multiple reaction monitoring mode (MRM) is the preferred technique for quantitation of PFAS traces (EU Recommendation No. 161 2010). The micro-HPLC technique provides higher peak capacity, greater resolution, increased sensitivity, and a higher speed of analysis compared to the conventional LC system (Guillarme et al. 2010), mainly in combination with MS/MS. Moreover, dispersive solid phase extraction ( $d$-SPE) is recommended, involving cleanup using combinations of anhydrous salt and various sorbents to remove interferences. This treatment has been used extensively in the last few years due to its simplicity, speed and effectiveness in cleaning up complex samples (Anastassiades et al. 2003; Surma et al. 2014a, b).

For this work, MS grade reagents, including methanol $(\mathrm{MeOH})$, acetonitrile $(\mathrm{MeCN})$ and formic acid $(\mathrm{FA})$, were purchased from Sigma Chemical Co. (St. Louis, MO, USA). Water was purified with a Milli-Q system (Millipore, Bedford, MA, USA). HPLC grade acetonitrile (for extraction) was purchased from Merck KGaA (Darmstadt, DE). Sodium chloride p.a. and magnesium sulphate anhydrous p.a. were purchased from POCh SA (Gliwice, PL). ENV (styrene-divinylbenzene) SPE bulk sorbent was obtained from Agilent Technologies (Santa Clara, CA, USA). Native (PFBA, PFPeA, PFHxA, PFHpA, PFOA, PFNA, PFDA, PFBS, PFHxS, PFOS) and labelled (LPFBA, L-PFHxA, L-PFOA, L-PFNA, L-PFDA, L-PFHxS, L-PFOS) PFAS solutions/mixtures were obtained from Wellington Laboratories (Guelph, ON, CA). Stock standard solutions (100 $\left.\mathrm{ng} \mathrm{mL}^{-1}\right)$ of native and labelled PFASs (IS-internal standard) were prepared in acetonitrile. Working standard solutions $\left(1 \mathrm{ng} \mathrm{mL}^{-1}\right)$ of native labelled PFASs were prepared in $20 \% \mathrm{MeOH}(\mathrm{v} / \mathrm{v})$ with $1 \%(\mathrm{v} / \mathrm{v})$ formic acid.

The micro-HPLC system (LC200, Eksigent, Vaughan, ON, CA) consisted of a multi-channel pump, an autosampler (set at $4^{\circ} \mathrm{C}$ ), and a column oven. A system controller coupled with a mass spectrometer (QTRAP 5500, AB SCIEX, Concord, ON, CA) consisting of a triple quadrupole, ion trap and ion source for electro-spray ionization (ESI), and controlled by the Analyst 1.5.1 software, was used to perform the LC-MS/MS analyses. All chromatographic determinations were performed on a HALO $\mathrm{C}_{18}$ $(50 \mathrm{~mm} \times 0.5 \mathrm{~mm} \times 2.7 \mu \mathrm{m})$ column (Eksigent) at $45^{\circ} \mathrm{C}$, at a flow rate of $20 \mu \mathrm{L} \mathrm{min}{ }^{-1}$. The compounds were eluted in a gradient system composed of water/formic acid (99.0/ 1.0, phase A) and acetonitrile/formic acid (99.0/1.0, phase B). The following gradient was used: $40 \% \mathrm{~B}(0-0.5 \mathrm{~min})$, $40 \%-90 \%$ B $(0.5-3.0 \mathrm{~min}), 90 \%$ B $\quad(3.0-4.0 \mathrm{~min})$, $90 \%-40 \%(4.0-4.2 \mathrm{~min})$ and $40 \%(4.2-5.0 \mathrm{~min})$. Qualitative and quantitative analyses were performed using the 
multiple reaction monitoring (MRM) method. Optimal identification of analyzed compounds was achieved under the following conditions: negative ionization, curtain gas: $25 \mathrm{~L} \mathrm{~min}{ }^{-1}$, collision gas: $9 \mathrm{~L} \mathrm{~min}^{-1}$, ion spray voltage: $-4500 \mathrm{~V}$, temperature: $350^{\circ} \mathrm{C}, 1$ ion source gas: $30 \mathrm{~L} / \mathrm{min}$, 2 ion source gas: $35 \mathrm{~L} / \mathrm{min}$, declustering potential: $-30:-85 \mathrm{~V}$, entrance potential: $-10 \mathrm{~V}$, collision energy: $-10:-65 \mathrm{eV}$, collision cell exit potential: $-10:-38 \mathrm{~V}$. An MPW 351R Centrifuge (MPW Med. Instruments, Warsaw, PL) was used for sample preparation. The vacuum concentrator plus (Eppendorf AG, Hamburg, DE) was used for concentrating extracts.

The honey sample preparation for PFAS-determination, based on $d$-SPE followed by micro-HPLC-MS/MS, was conducted according to the methodology evaluated and validated in a previous study (Surma et al. 2015). Briefly, $5 \mathrm{~g}$ of honey was weighed into a $50-\mathrm{mL}$ centrifuge tube, spiked with $250 \mu \mathrm{l}$ of $100 \mathrm{ng} \mathrm{mL}^{-1}$ IS solution (L-PFBA, L-PFHxA, L-PFOA, L-PFNA, L-PFDA, L-PFHxS, L-PFOS), and $5 \mathrm{~mL}$ of warm water $\left(50^{\circ} \mathrm{C}\right)$ was added to the sample. After cooling to room temperature, $10 \mathrm{~mL}$ of acetonitrile $(\mathrm{MeCN})$ and $150 \mu \mathrm{L}$ of formic acid (FA) were added. The whole tube was vigorously shaken for $1 \mathrm{~min}$, after which $1 \mathrm{~g}$ of $\mathrm{NaCl}$ and $4 \mathrm{~g}$ of $\mathrm{MgSO}_{4}$ were added. This was followed by shaking for $1 \mathrm{~min}$, and the solution was finally centrifuged for $15 \mathrm{~min}$ at $8700 \mathrm{RCF}$. Exactly $6 \mathrm{~mL}$ of the supernatant was placed in a $15-\mathrm{mL}$ tube, previously prepared with $0.15 \mathrm{~g}$ ENV SPE bulk sorbent and $0.900 \mathrm{~g} \mathrm{MgSO}_{4}$. After $30 \mathrm{~s}$ of shaking and $5 \mathrm{~min}$ of centrifugation at $5000 \mathrm{RCF}, 4 \mathrm{~mL}$ of supernatant was transferred into a screw cap vial and evaporated to dryness under a stream of $\mathrm{N}_{2}$ at $40^{\circ} \mathrm{C}$. Residues were dissolved in $1 \mathrm{~mL}$ of methanol. Just before injection, the samples were diluted fivefold in acidified $\mathrm{dH}_{2} \mathrm{O}$ (distillate water with $1 \%$ (v/v) formic acid). Finally, all cleaned-up samples were analyzed by micro-HPLC-MS/MS. Blank samples (to determine recoveries) and reagent blanks were prepared according to the same procedure. Each sample was prepared in triplicate.

A series of standard solutions was prepared in triplicate by diluting the standard mixture solution in $20 \% \mathrm{MeOH}$ $(\mathrm{v} / \mathrm{v})$ with $1 \%(\mathrm{v} / \mathrm{v})$ formic acid in the range of 1-20 ng mL ${ }^{-1}$. Then, $20 \mu \mathrm{L}$ of the labelled PFAS solution (100 $\mathrm{ng} \mathrm{mL}^{-1}$ ) was added to each standard solution.

Food matrices with certified concentrations of perfluoroalkyl substances for honey and related food are not commonly available at the present time. Thus, the usefulness of the method was verified on the basis of the recovery ratio of analyzed compounds (analysis of spiked samples). Recovery studies involved spiking homogenized samples of flower honey with the standard solution of investigated PFASs to a fortification level of $0.001 \mathrm{mg} \mathrm{kg}^{-1}$.
The PFASs were identified by retention time $\left(\mathrm{R}_{\mathrm{t}}\right)$ and MRM (multiple reaction monitoring) ion pairs. Calibration curves were constructed by calculating the ratio of the peak area versus the peak area of appropriate labelled PFASs against analyte concentration. Investigated analytes were evaluated with the help of assigned labelled PFASs as follows: PFOA/L-PFOA, PFHpA/L-PFOA, PFNA/LPFNA, PFDA/L-PFDA, PFHxS/L-PFHxS, and PFOS/LPFOS.

The analyzed samples of honey were purchased from the local market and were originally packed in tightly closed glass jars. Typically collected honey jars ranged in size from 100 to $250 \mathrm{~g}$. The honey samples were stored in a dry place at room temperature. Just after opening, the jar contents were thoroughly mixed until homogeneous, and then $5 \mathrm{~g}$ of sample was weighed into a $50-\mathrm{mL}$ centrifuge tube.

Several precautions were taken to avoid cross-contamination from sampling and during analysis. During the entire analytical process, the plastic materials (Eppendorf, centrifuge tube) were sourced only from the Sarstedt Company (Nümbrecht, DE) because these did not show a background signal in subsequent analyses. All plastics and dishes used were disposable, but sterilization was avoided due to the possibility of releasing certain constituents of the plastic materials into stored solutions, which might result in contamination of the sample and an increase in the analytical background. All used dishes were always protected against dust, which can be a source of contamination by perfluoroalkyl substances.

\section{Results and Discussion}

The recovery values, limits of detection (LODs), and limits of quantification (LOQs) determined for PFASs are shown in Table 1. Recovery values of selected PFASs were determined for floral honey samples fortified at a level of $0.001 \mathrm{mg} \mathrm{kg}^{-1}$. They ranged from $75 \%$ for PFBA to $93 \%$ for PFNA for all tested analytes.

The recovery values found for all tested analytes were in good agreement with Commission Recommendation 2010/ $161 / \mathrm{EU}$, indicating that Member States should carry out the analysis of perfluoroalkylated substances in accordance with Annex III to Regulation (EC) No. 882/2004 of the European Parliament and of the Council of 29 April 2004 on official controls performed, to ensure verification of compliance with feed and food laws and animal health and welfare rules, by making use of a method of analysis that has been proven to generate reliable results. Ideally, the recommended recovery rates should be within the range of $70 \%-120 \%$. 
Table 1 The recovery values, LODs, and LOQs for determined PFASs

\begin{tabular}{lllll}
\hline PFASs Name & Acronym & LOD $\left(\mathrm{ng} \mathrm{g}^{-1}\right.$ ww) & LOQ $\left(\mathrm{ng} \mathrm{g}^{-1}\right.$ ww) & Recovery (\%) \\
\hline Perfluorobutanoic acid & PFBA & 0.023 & 0.069 & 75 \\
Perfluoropentanoic acid & PFPeA & 0.025 & 0.075 & 82 \\
Perfluorobutane sulfonate & PFBS & 0.021 & 0.063 & 91 \\
Perfluorohexanoic acid & PFHxA & 0.015 & 0.045 & 87 \\
Perfluoroheptanoic acid & PFHpA & 0.017 & 0.051 & 91 \\
Perfluorooctanoic acid & PFOA & 0.016 & 0.052 & 82 \\
Perfluorohexane sulfonate & PFHxS & 0.014 & 0.042 & 79 \\
Perfluorononanoic acid & PFNA & 0.019 & 0.057 & 93 \\
Perfluorodecanoic acid & PFDA & 0.018 & 0.054 & 89 \\
Perfluorooctane sulfonate & PFOS & 0.040 & 0.134 & 84 \\
\hline
\end{tabular}

In this study, LOQ values for all tested perfluoroalkyl substances ranged from $0.042 \mathrm{ng} \mathrm{g}^{-1}$ ww for PFHxS to $0.134 \mathrm{ng} \mathrm{g}^{-1} \mathrm{ww}$ for PFOS. The obtained values are in good agreement with the LOQ value $\left(1 \mu \mathrm{g} \mathrm{kg}^{-1}\right)$ recommended by Commission Recommendation 2010/161/EU.

A breakdown of the concentrations of the studied compounds found in the studied samples is shown in Table 2. The results are the mean and standard deviations of three independent extractions $(\mathrm{n}=3)$.

Apart from three honey samples (English wildflower B, Spanish orange blossom and French linden), perfluoroalkyl carboxylic acids (PFCAs) were detected in almost all analyzed honey samples in the range from $0.124 \mathrm{ng} \mathrm{g}^{-1}$ ww for English wildflower A to $0.798 \mathrm{ng} \mathrm{g}^{-1}$ ww for Italian eucalyptus, which is presented in Fig. 1.

The percent values of samples (\%) in which particular PFCAs were found increased in the following order: PFDA (3.8) $<$ PFNA (23.1) < PFOA (46.2) $<$ PFHpA (61.5). PFHpA was mostly detected in Polish and Slovak honey samples with a mean of 0.309 and $0.191 \mathrm{ng} \mathrm{g}^{-1}$ ww, respectively. It was also found in individual samples of Scottish (clover), English (heather), Spanish (lemon blossom and thyme), and Italian (eucalyptus) honey. PFOA was primarily quantified in Spanish honey samples with a mean of $0.187 \mathrm{ng} \mathrm{g}^{-1}$ ww. It was also present in samples from Scotland (heather and multiflorous), England (heather and wildflower), Frence (chestnut and acacia), and Italy (eucalyptus). PFNA as well as PFOA were primarily determined in honey from Spain, with values in the range from $0.071 \mathrm{ng} \mathrm{g}^{-1} \mathrm{ww}$ for thyme to $0.253 \mathrm{ng} \mathrm{g}^{-1} \mathrm{ww}$ for heather. Moreover, it was identified in French acacia $\left(0.113 \mathrm{ng} \mathrm{g}^{-1} \mathrm{ww}\right)$ and Italian eucalyptus $\left(0.149 \mathrm{ng} \mathrm{g}^{-1}\right.$ ww) honey. PFDA was quantified in only one honey sample, Italian eucalyptus, at a level of $0.278 \mathrm{ng} \mathrm{g}^{-1} \mathrm{ww}$. Among perfluoroalkane sulfonates (PFSAs), only PFHxS was quantified in four honey samples and ranged from $0.080 \mathrm{ng} \mathrm{g}^{-1} \mathrm{ww}$ to $0.191 \mathrm{ng} \mathrm{g}^{-1}$ ww for Italian eucalyptus and Spanish heather, respectively. PFOS was detected in only three honey samples (Italian eucalyptus, and Spanish heather and lavender); however, the concentrations were below LOQ. Italian eucalyptus honey was characterized by the highest variety and total content of PFASs.

Considering the honey type, the level of contamination with PFOA in heather honey was the same in samples from Scotland, England, and Spain. PFHpA was detected only in English honey, with a higher amount in the A brand sample. PFNA (0.253 $\mathrm{ng} \mathrm{g}^{-1}$ ww) and PFHxS (0.014 $\mathrm{ng} \mathrm{g}^{-1}$ ww) were only identified in Spanish honey. Only two PFASs were found in multiflorous honey: PFOA in the Scottish sample (0.134 $\left.\mathrm{ng} \mathrm{g}^{-1} \mathrm{ww}\right)$ and PFFpA in the Slovak sample $\left(0.170 \mathrm{ng} \mathrm{g}^{-1} \mathrm{ww}\right)$ and in both Polish honey samples, from Malopolska $\left(0.218 \mathrm{ng} \mathrm{g}^{-1} \mathrm{ww}\right)$ and the Warmia and Mazury $\left(0.183 \mathrm{ng} \mathrm{g}^{-1}\right.$ ww) regions. In linden honey samples, also originating from these two Polish regions, the PFHpA concentration was 0.353 and $0.263 \mathrm{ng} \mathrm{g}^{-1} \mathrm{ww}$, respectively. The results indicate that honey samples from the two Polish regions are diverse in terms of contaminated by PFASs. A higher concentration of PFCAs was noticed in Malopolska (industrialized region of Poland) honey compared to that from Warmia and Mazury (regarded as the least polluted region of Poland, also called the "green lungs of Poland").

From the perspective of regions of origin for the various honey samples (eastern Europe-Poland and Slovakia; southern Europe-Italy, France and Spain; northern Europe-Scotland and England), it was observed that the level of PFCA contamination slightly increased in the following order: northern European countries < eastern European countries $<$ southern European countries. However, examining the average content of perfluoroalkyl carboxylic acid in these parts of Europe, no statistically significant differences were observed. Values of $0.256 \pm 0.227 \mathrm{ng} \mathrm{g}^{-1}$ ww, $0.262 \pm 0.099 \mathrm{ng} \mathrm{g}^{-1}$ ww and $0.385 \pm 0.265 \mathrm{ng} \mathrm{g}^{-1}$ ww were obtained for northern, eastern and southern European countries, respectively. In contrast to the results obtained from the two regions of Poland, the honey samples originating from three geographic regions of Europe, 
Table 2 Content of selected PFASs in analyzed honey samples (ng $\left.\mathrm{g}^{-1} \mathrm{ww}\right)$

\begin{tabular}{|c|c|c|c|c|c|c|c|c|c|c|c|c|c|}
\hline \multicolumn{2}{|l|}{ Honey sample } & \multicolumn{8}{|l|}{ PFCAs } & \multicolumn{4}{|l|}{ PFSAs } \\
\hline & & \multicolumn{2}{|l|}{ PFOA } & \multicolumn{2}{|c|}{ PFHрA } & \multicolumn{2}{|l|}{ PFNA } & \multicolumn{2}{|l|}{ PFDA } & \multicolumn{2}{|l|}{ PFHxS } & \multicolumn{2}{|l|}{ PFOS } \\
\hline Type & Country of origin & Mean & SD & Mean & SD & Mean & SD & Mean & SD & Mean & SD & Mean & SD \\
\hline \multirow[t]{4}{*}{ Heather } & Scotland & 0.221 & 0.017 & nd & - & nd & - & nd & - & nd & - & nd & - \\
\hline & England A & 0.295 & 0.023 & 0.413 & 0.008 & nd & - & nd & - & nd & - & nd & - \\
\hline & England B & nd & - & 0.287 & 0.006 & nd & - & nd & - & nd & - & nd & - \\
\hline & Spain & 0.223 & 0.014 & nd & - & 0.253 & 0.021 & nd & - & 0.191 & 0.014 & $<\mathrm{LOQ}$ & - \\
\hline Clover & Scotland & nd & - & 0.317 & 0.023 & nd & - & nd & - & nd & - & nd & - \\
\hline \multirow[t]{2}{*}{ Wildflower } & England A & 0.124 & 0.007 & nd & - & nd & - & nd & - & nd & - & nd & - \\
\hline & England B & nd & - & nd & - & nd & - & nd & - & nd & - & nd & - \\
\hline \multirow[t]{4}{*}{ Multiflorous } & Poland M & nd & - & 0.218 & 0.001 & nd & - & nd & - & nd & - & nd & - \\
\hline & Poland W & nd & - & 0.183 & 0.002 & nd & - & nd & - & nd & - & nd & - \\
\hline & Scotland & 0.134 & 0.013 & - & - & nd & - & nd & - & nd & - & nd & - \\
\hline & Slovakia & nd & - & 0.170 & 0.015 & nd & - & nd & - & nd & - & nd & - \\
\hline \multirow[t]{3}{*}{ Linden } & Poland M & nd & - & 0.353 & 0.028 & nd & - & nd & - & nd & - & nd & - \\
\hline & Poland W & nd & - & 0.263 & 0.012 & nd & - & nd & - & nd & - & nd & - \\
\hline & France & nd & - & nd & - & nd & - & nd & - & nd & - & nd & - \\
\hline \multirow[t]{2}{*}{ Rape } & Poland M & nd & - & 0.443 & 0.026 & nd & - & nd & - & nd & - & nd & - \\
\hline & Slovakia & nd & - & 0.201 & 0.007 & nd & - & nd & - & nd & - & nd & - \\
\hline Buckwheat & Poland W & nd & - & 0.395 & 0.010 & nd & - & nd & - & nd & - & nd & - \\
\hline Forest & Slovakia & nd & - & 0.203 & 0.005 & nd & - & nd & - & nd & - & nd & - \\
\hline Honeydew & Slovakia & nd & - & 0.190 & 0.005 & nd & - & nd & - & nd & - & nd & - \\
\hline Lemon blossom & Spain & 0.326 & 0.010 & 0.135 & 0.012 & 0.174 & 0.017 & nd & - & 0.116 & 0.008 & nd & - \\
\hline Orange blossom & Spain & 0.047 & 0.004 & nd & - & nd & - & nd & - & nd & - & nd & - \\
\hline Thyme & Spain & 0.167 & 0.004 & 0.309 & 0.010 & 0.071 & 0.004 & nd & - & 0.132 & 0.012 & nd & - \\
\hline Eucalyptus & Italy & 0.121 & 0.002 & 0.250 & 0.001 & 0.149 & 0.010 & 0.278 & 0.019 & 0.080 & 0.002 & $<\mathrm{LOQ}$ & - \\
\hline Chestnut & France & 0.345 & 0.012 & nd & - & nd & - & nd & - & $<\mathrm{LOQ}$ & - & nd & - \\
\hline Acacia & France & 0.103 & 0.005 & nd & - & 0.113 & 0.003 & nd & - & nd & - & nd & - \\
\hline Lavender & Spain & 0.162 & 0.014 & nd & - & 0.225 & 0.021 & nd & - & nd & - & $<\mathrm{LOQ}$ & - \\
\hline
\end{tabular}

PFBA, PFPeA, PFHxA and PFBS were not detected in any honey samples

$S D$ standard deviation, $n d$ not detected A, $B$ brand of honey, $M$ honey from Malopolska region, $W$ honey from Warmia and Mazury region

differing in climatic, environmental, and socio-economic conditions, showed no regional impact on PFAS contamination levels.

A review of the literature revealed very little information about the contamination of honey with PFASs. PFOA and PFOS in four Italian honey samples from the Mount Amiata area were analyzed by Guerranti et al. (2013). No positive results were obtained. The investigated analytes were below the detection limit $\left(0.5 \mathrm{ng} \mathrm{g}^{-1} \mathrm{ww}\right)$. According to the Scientific Report of EFSA (EFSA 2011) on the results of monitoring perfluoroalkylated substances in food during the period 2000-2009, 30 honey samples were tested for PFOA and PFOS content. The level of PFOA ranged between 0.25 and $0.47 \mathrm{ng} \mathrm{g}^{-1}$. Another EFSA Scientific Report (EFSA 2012) covered the occurrence and dietary exposure to perfluoroalkylated substances via food. The above assessment was based on 54195 analytical results obtained for 7560 food samples covering a list of 27 PFASs, but not all samples were analyzed for the full set of PFASs. The data were submitted by 13 European countries for samples collected in the period 2006-2012. Four of 39 honey samples analyzed for PFOA provided quantifiable results in the range from 2 to $470 \mathrm{ng} \mathrm{kg}^{-1}$. PFDA was quantified in one honey sample $\left(8 \mathrm{ng} \mathrm{kg}^{-1}\right)$. Similarly, PFHxA (24 $\left.\mathrm{ng} \mathrm{kg}^{-1}\right)$ and PFOS $\left(55 \mu \mathrm{g} \mathrm{kg}^{-1}\right)$ were found only in one sample.

In our study, the quantity of PFOAs was found to be in the range from $0.047 \mathrm{ng} \mathrm{g}^{-1}$ for Spanish orange blossom to $0.345 \mathrm{ng} \mathrm{g}^{-1}$ for French chestnut. We can conclude that PFOA content was at a similar level in all studies. PFDA was also quantified only in one honey sample of Italian eucalyptus $\left(0.278 \mathrm{ng} \mathrm{g}^{-1}\right)$, but its content was approximately 35 times higher than that reported by the EFSA (EFSA, 2012). PFHxA and PFOS were not quantified in this study. 


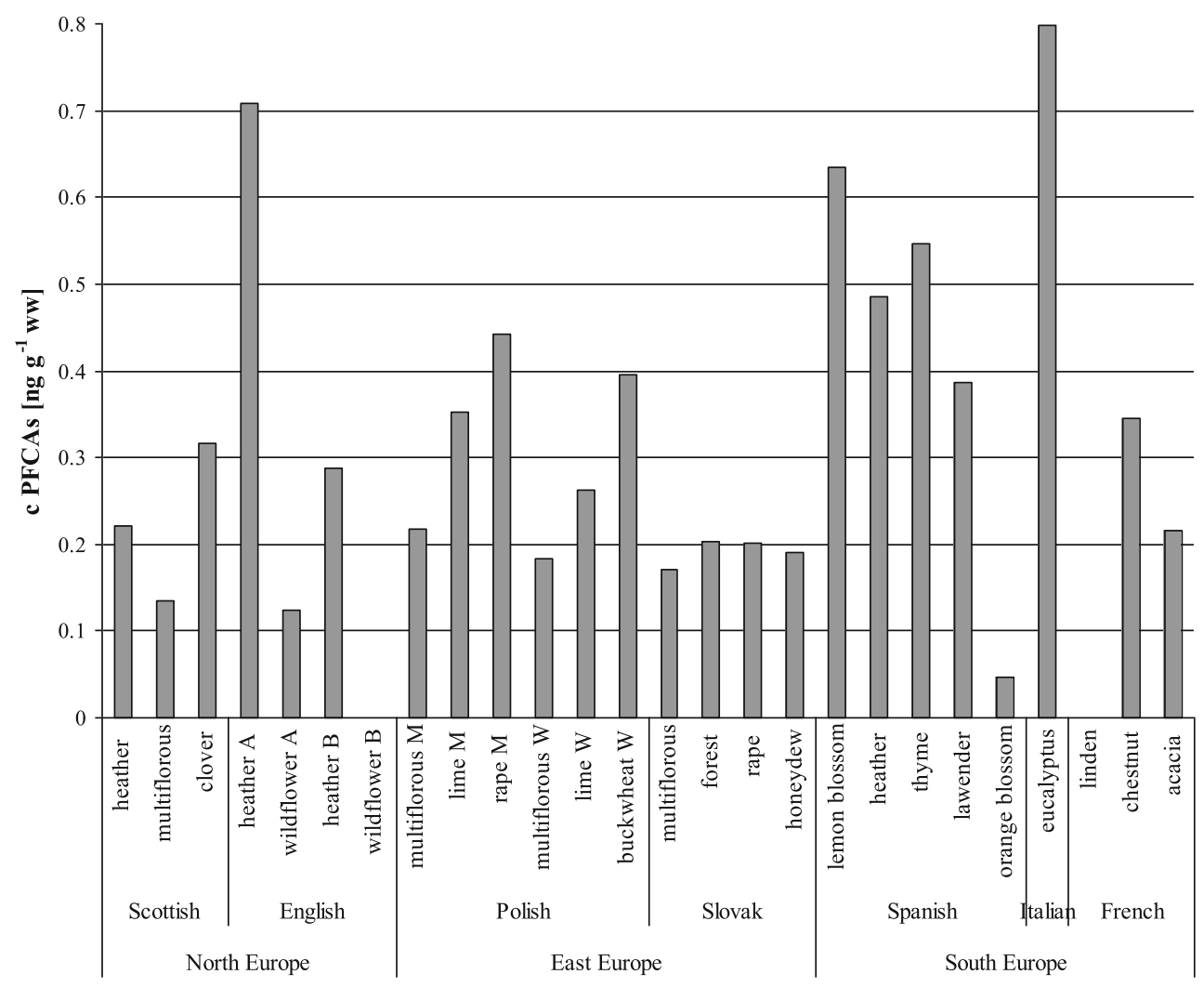

Fig. 1 The total content of PFCAs in investigated honey

An analytical method based on dispersive solid phase extraction ( $d$-SPE) and micro-HPLC-MS/MS detection was successfully applied for determination of two main groups of PFASs in honey samples: perfluoroalkyl carboxylic acids (PFCAs) and perfluoroalkane sulfonates (PFSAs). The efficient use of the modified QuEChERS method with a polymer-based sorbent-ENV for efficient honey sample preparation-was demonstrated. The presented method is suitable for determination of PFASs in honey and can be extended to other food samples. It can be concluded that the presence of perfluoroalkyl substances in honey may serve as an indicator of environmental pollution.

Acknowledgments We gratefully acknowledge project Grants No. 2015/17/B/NZ9/01623 from the National Science Centre, Poland. The project was elaborated within the Mentoring Programme from Polish Science Foundation (53/U/SKILLS/2015). We thank Dr. Wiesław Wiczkowski from the Department of Chemistry and Biodynamics of Food of the Institute of Animal Reproduction and Food Research of Polish Academy of Sciences in Olsztyn for his help in the elaboration of the mass spectrometry methodology related to PFASs.

Open Access This article is distributed under the terms of the Creative Commons Attribution 4.0 International License (http://creative commons.org/licenses/by/4.0/), which permits unrestricted use, distribution, and reproduction in any medium, provided you give appropriate credit to the original author(s) and the source, provide a link to the Creative Commons license, and indicate if changes were made.

\section{References}

Aliferis KA, Tarantilis PA, Harizanis PC, Alissandrakis E (2010) Botanical discrimination and classification of honey samples applying gas chromatography/mass spectrometry fingerprinting of headspace volatile compounds. Food Chem 12:856-862. doi:10.1016/j.foodchem.2009.12.098

Anastassiades M, Maštovská K, Lehotay SJ (2003) Evaluation of analyte protectants to improve gas chromatographic analysis of pesticides. J Chromatogr A 1015(1-2):163-184. doi:10.1016/ S0021-9673(03)01208-1

Buck RC, Franklin J, Berger U, Condor JM, Cousins IT, de Voogt P, Jensen AA, Kannan K, Mabury SA, van Leeuwen van SP (2011) Perfluoroalkyl and polyfluoralkyl substances in the environment: terminology, classification, and origins. Integr Environ Assess Manag 7(4):513-541. doi:10.1002/ieam.258

Celli G, Maccagnani B (2003) Honey bees as bioindicators of environmental pollution. Bull Insectol 56:137-139

Commission Recommendation (2010/161/EU) of 17 March 2010 on the monitoring of perfluoroalkylated substances in food. Official Journal of the European Union L68/23

Del Gobbo L, Tittlemier S, Diamond M, Pepper K, Tague B, Yeudall F, Vanderlinden L (2008) Cooking decreases observed perfluorinated compound concentrations in fish. J Agric Food Chem 56(16):7551-7559. doi: $10.1021 / \mathrm{jf} 800827 \mathrm{r}$

Domingo JL (2012) Healthrisks of dietary exposure to perfluorinated compounds. Environ Int 40:187-195. doi:10.1016/j.envint.2011. 08.001

EFSA, European Food Safety Authority (2008) Perfluorooctane sulfonate (PFOS), perfluorooctanoic acid (PFOA) and their salts. 
Scientific opinion of the panel on contaminants in the food chain. The EFSA J 653:1-131

EFSA, European Food Safety Authority (2011) Results of the monitoring of perfluoroalkylated substances in food in the period 2000-2009. The EFSA J 9(2):2016-2049

EFSA, European Food Safety Authority (2012) Perfluoroalkylated substances in food: occurrence and dietary exposure. The EFSA J 10(6):2743-2798

Ericson I, Nadal M, Van Bavel B, Lindström G, Domingo JL (2008) Levels of perfluorochemicals in water samples from Catalonia, Spain: is drinking water a significant contribution to human exposure? Environ Sci Pollut Res 15(7):614-619. doi:10.1007/ s11356-008-0040-1

Finola MS, Lasagno MC, Marioli JM (2007) Microbiological and chemical characterization of honey from central Argentina. Food Chem 100(4):1649-1653. doi:10.1016/j.foodchem.2005.12.046

Gellrich V, Brunn H, Stahl T (2013) Perfluoroalkyl and polyfluoroalkyl substances (PFASs) in mineral water and tap water. J Environ Sci Health A Tox Hazard Subst Environ Eng 48:129-135. doi:10.1080/10934529.2013.719431

Guerranti C, Perra G, Corsolini S, Focardi SE (2013) Pilot study on levels of perfluorooctane sulfonic acid (PFOS) and perfluorooctanoic acid (PFOA) in selected foodstuffs and human milk from Italy. Food Chem 140(1-2):197-203. doi:10.1016/j.foodchem. 2012.12.066

Guillarme D, Ruta J, Rudaz S, Veuthey JL (2010) New trends in fast and high-resolution liquid chromatography: a critical comparison of existing approaches. Anal Bioanal Chem 397(3):1069-1082. doi:10.1007/s00216-009-3305-8

Huttunen S, Riihinen K, Kauhanen J, Tikkanen-Kaukanen K (2012) Antimicrobial activity of different Finnish monofloral honeys against human pathogenic bacteria. APMIS 121:827-834. doi:10.1111/apm.12039

Kärrman A, Ericson I, van Bavel B, Darnerud PO, Aune M, Glynn A, Lignell S, Lindström G (2007) Exposure of perfluorinated chemicals through lactation: levels of matched human milk and serum and a temporal trend, 1996-2004 Sweden. Environ Health Perspect 115(2):226-230. doi:10.1289/ehp.9491
Kujawski MW, Namieśnik J (2008) Challenges in preparing honey samples for chromatographic determination of contaminants and trace residues. TrAC-Trends Anal Chem 27(9):785-793. doi:10. 1016/j.trac.2008.07.004

Kwakman PH, Van den Akker JP, Güçlü A, Aslami H, Binnekade JM, de Boer L, Boszhard L, Paulus F, Middelhoek P, te Velde AA, Vandenbroucke-Grauls CMJE, Schultz MJ, Zaat SAJ (2008) Medical-grade honey kills antibiotic-resistant bacteria in vitro and eradicates skin colonization. Clin Infect Dis 46:1677-1682. doi: $10.1086 / 587892$

Mercan N, Guvensen A, Celik A, Katircioglu H (2007) Antimicrobial activity and pollen composition of honey samples collected from different provinces in Turkey. Nat Prod Res 21:187-195. doi:10. 1080/14786410600906277

Stahl T, Mattern D, Brunn H (2011) Toxicology of perfluorinated compounds. Environ Sci Eur 23(1):38. doi:10.1186/2190-471523-38

Surma M, Zieliński H (2015) What do we know about the risk arising from perfluorinated compounds. Pol J Environ Stud 24:11-19. doi: $10.15244 /$ pjoes/30929

Surma M, Sadowska-Rociek A, Cieślik E (2014a) Evaluation of the QuEChERS method with GC-MS detection for the determination of organochlorine pesticides in food of animal origin. Food Annal Methods 7(2):366-376. doi:10.1007/s12161-013-9635-3

Surma M, Sadowska-Rociek A, Cieślik E (2014b) The application of d-SPE in the QuEChERS method for the determination of PAHs in food of animal origin with GC-MS detection. Eur Food Res Technol 238(6):1029-1036. doi:10.1007/s00217-014-2181-4

Surma M, Wiczkowski W, Cieślik E, Zieliński H (2015) Method dvelopment for the determination of PFOA and PFOS in honey based on the dispersive solid phase extraction ( $d$-SPE) with microUHPLC-MS/MS system. Microchemical MJ 121:150-156. doi:10.1016/j.microc.2015.02.008

Zhao YG, Wonga CKC, Wonga MH (2012) Environmental contamination, human exposure and body loadings of perfluorooctane sulfonate (PFOS), focusing on Asian countries. Chemosphere 89(4):355-368. doi:10.1016/j.chemosphere.2012.05.043 